\title{
Further validation of the Health Scale of Traditional Chinese Medicine (HSTCM)
}

\author{
Darong $\mathrm{Wu}^{1}$, Shilong Lai*1,2, Luojing Zhou ${ }^{1}$, Xinfeng Guo ${ }^{2}$, Weixiong Liang ${ }^{2}$, \\ Zehuai Wen ${ }^{2}$, Aihua Ou${ }^{1}$, Guangqing Zhang ${ }^{1}$ and Keji Chen ${ }^{3}$
}

Address: ${ }^{1}$ Second Affiliated Hospital of the Guangzhou University of Chinese Medicine, Guangzhou, PR China, ${ }^{2}$ Guangzhou University of Chinese Medicine, Guangzhou, PR China and ${ }^{3}$ Xiyuan Hospital, China Academy of Chinese Medical Sciences, Beijing, PR China

Email: Darong Wu - darongwu@163.com; Shilong Lai* - gzxuntcm@pub.guangzhou.gd.cn; Luojing Zhou - luojing76@163.com; Xinfeng Guo - drguoguo@gmail.com; Weixiong Liang - liangwx@pub.guangzhou.gd.cn; Zehuai Wen - wenzehuy@pub.guangzhou.gd.cn; Aihua Ou - ouaihua@21cn.com; Guangqing Zhang - hlbzhang@126.com; Keji Chen - chen.keji@gmail.com

* Corresponding author

Published: 30 April 2009

Chinese Medicine 2009, 4:8 doi:10.1 186/1749-8546-4-8

This article is available from: http://www.cmjournal.org/content/4/l/8

(c) 2009 Wu et al; licensee BioMed Central Ltd.

This is an Open Access article distributed under the terms of the Creative Commons Attribution License (http://creativecommons.org/licenses/by/2.0), which permits unrestricted use, distribution, and reproduction in any medium, provided the original work is properly cited.
Received: 7 November 2008

Accepted: 30 April 2009

\begin{abstract}
Background: Few health measurement scales are based on Chinese medicine theory. The Health Scale of Traditional Chinese Medicine (HSTCM) was developed to fill this gap. The aim of this study is to validate the HSTCM.

Methods: A convenience sample of 630 participants was recruited in II settings. All participants were asked to complete the HSTCM and World Health Organization Quality of Life MeasureAbbreviated Version (WHOQOL-BREF).

Results: Properties of the HSTCM were tested. Intra-class correlation coefficient representing the inter-interviewer reliability was $0.99(95 \% \mathrm{Cl})$ for the overall instrument. Spearman-Brown correlation coefficient and Cronbach's coefficient alpha were $0.8 \mathrm{I}$ and 0.94 respectively, indicating satisfactory internal reliability and inter-interviewer reliability. Spearman's rho correlation coefficient between the HSTCM and WHOQOL-BREFF was -0.67. A receiver operating characteristic (ROC) curve analysis was performed to test the discriminate validation. Areas under the ROC curve analysis for the HSTCM and its domains ranged $0.71-0.87$ and all the lower levels of $95 \% \mathrm{Cl}$ were greater than 0.50 .
\end{abstract}

Conclusion: The HSTCM was validated as a generic health scale and may complement existing health measurement scales in Chinese medicine health care.

\section{Background}

Acceptance of health measurement scales based on one's perception has increased in recent years [1-3]. Several well-established measures on health status or healthrelated Quality of Life (QOL) have been widely used [4-8]; however, few were developed on the basis of Chinese medicine which has been important for the well-being of the Chinese people for many years [9] and is now increasingly recognized worldwide [10-12].

Measuring health in accordance with Chinese medicine theory is useful $[13,14]$. Chinese medicine practitioners pay close attention to patients' subjective feelings for diagnosis and treatment. Different perspectives of the patients 
may lead to different prescriptions from the practitioner even if the patients suffer from the same condition [15]. Over the years, Chinese medicine practitioners have accumulated valuable experiences on obtaining information from the patient's perspective that may benefit their treatment strategy and judgment of clinical efficacy. We believe that these experiences can be more easily understood by clinicians and researchers if they were involved in some applicable instruments. Moreover, Chinese medicine and Western medicine work differently towards the end result. In Chinese medicine, information such as adaptation to climates and seasons, aversion to cold, positive feelings concerning the ability of maintaining stable mood is carefully captured as evidence for patients' adaptability with both natural and social environments. Although modern Chinese medicine practitioners may take biomarkers as references, there is a general impression among them that indicators reflect individual's adaptability may possess a more important position when testing the efficacy of a Chinese medicine treatment.

However, these indicators are usually not involved in common patient reported outcomes (PRO) or health related quality of life measures. A few other instruments were developed on the basis of Chinese medicine theory or for integrative medical research but none of them were based on a community sample $[16,17]$. In addition, the commonly recognized and accepted set of standardized procedures $[18,19]$, from concept to measurement scale, makes it possible to develop an instrument based on Chinese medicine theory.

The Health Scale of Traditional Chinese Medicine (HSTCM), which is a generic scale designed for evaluating general health according to subjective feelings [20], is based on health concept of Chinese medicine and the operationalization of this concept's measurement $[20,21]$. The HSTCM consists of three domains, namely physical function under natural environment (PFNE), spirit (SP) and social environment (SE), and 2 additional items (see Additional file 1). PFNE domain has four facets: physical functioning (PF), voice (VOC), stool and urine (SU), and adaptability of natural environment (ANE). SP domain also has four facets: confidence and content (CC), self-confidence (SC), energy (EG) and basic ability of thinking (BAT). SE domain has three facets: ability of communicating with people (ACP), adaptability of noisy condition (ANC) and ability of dealing with bad stimulations (ADBS). In 2003, the development of initial Health Scale of Traditional Chinese Medicine (iHSTCM) [20] and the refinement from the iHSTCM (88 items) to HSTCM (47 items) [21] were accomplished. It was shown that the HSTCM was conceptually sound and reliable [22]. However, the test of psychometric properties using various independent samples may still be needed, partic- ularly construct validation, according to the principles of instrument development $[23,24]$. Meanwhile, the previous test was based on data collected through iHSTCM (containing 88 items $[21,22]$ ); it is reasonable to test the psychometric properties again with the revised version of HSTCM (containing 47 items).

The purpose of developing the HSTCM is similar to other generic health related QOL measures, e.g. the World Health Organization Quality of Life Measure-Abbreviated Version (WHOQOL-BREF) [25] and MOS 36-Item Short Form (SF-36) [6]. We used the WHOQOL-BREF (Chinese version) [26] as a comparison instrument when examining the validation of the HSTCM because of the excellent validity and reliability of the WHOQOL-BREF. It is also because the Chinese version of the WHOQOL-BREF has become one of the standard measurements of QOL in China.

The aim of this study is to validate the measurement properties of the HSTCM in a convenience sample.

\section{Methods \\ Participants}

Inclusion criteria for the participants are (a) 18 years of age or above and (b) speaking Putonghua (Mandarin Chinese). All participants were asked to complete both the HSTCM and WHOQOL-BREF. An oral agreement was obtained from each participant prior to interview.

\section{Study instruments}

The HSTCM includes 47 items, each with a five-degree response format, scoring 1, 2, 3, 4 and 5 respectively. Total scores range 0-225 (two additional items not included), whereby a high score indicates poor health. The Chinese version of the WHOQOL-BREF (Ministry of Health, China, 1999) [26] was taken in this study as a standard criterion. The instrument contains 26 core items and three additional items. The three additional items are only used in the mainland Chinese version.

\section{Demographics}

A demographic questionnaire covering gender, age, and highest educational attainment was provided at the end of the interview. Each participant completed the questionnaire in the presence of an interviewer.

\section{Quality control of data collection}

We produced a booklet entitled the Guide to the HSTCM Survey to set forth a standard operating procedure (SOP), rules of investigation, structured response to frequently asked questions for interviewers and structured oral interview guidance. A total of 25 interviewers, who were senior medical students or nurses, were trained with the booklet for 4-6 hours. 


\section{Data management and analysis}

We compiled a coding notebook to ensure good quality of data entry. If there are two answers to one question that are next to each other, the auditor must choose one of the answers. However, if the two answers are not next to each other, the auditor must read the notes from the interviewers. If there are no related notes, the auditor must consider the answer as missing.

All data were double entered with EPI DATA 2.1a (EpiData Association Odense, Denmark). The final dataset was converted into SPSS format. Data were analyzed primarily with SPSS version 11.0 (SPSS, USA) while confirmatory factor analysis was performed with SPSS Amos 4.0. Demographic data were assessed with descriptive statistics. Reliability assessment was conducted between interviewers. Twenty-four of the 25 interviewers were divided into 12 pairs, two in one pair. A pair of interviewers questioned a participant and it was ensured that they could not see each other's records. One of them was in charge of the investigation, while the other recorded the answers only. It was decided randomly who would be in charge. Interinterviewer reliability was performed by intra-class correlation coefficient (ICC) analysis. Cronbach's $\alpha$ statistics were used to assess the internal consistency reliability of the HSTCM, in which values greater than 0.6 were considered evidence of internal consistency [27]. Unequallength Spearman-Brown prophecy coefficient was used to obtain the split-half reliability coefficient [28].

Using input from both the HSTCM focus groups and Chinese medicine practitioners, we performed the face and content validation during the design phase of the HSTCM [21] to assess how well the HSTCM measured the concepts. The HSTCM was further verified after the design phase with input from healthy participants and inpatients of Chinese medicine hospitals to ensure the questions' relevance.

Convergent validation of the HSTCM was assessed with Spearman's rho correlation coefficients between the scores of the HSTCM and WHOQOL-BREF. An absolute value within the range of $0.4-0.8$ suggests that the convergent validation is appropriate [23].

To study the ability of the domain and overall HSTCM scores in discriminating groups of participants of possibly different health status, we divided the participants into three groups according to their self-reported general health status, self-reported health status change and degree of medical needs. The mean, standard deviation (SD) and 95\% confidence interval (95\%CI) of domain and overall HSTCM scores of each group were calculated. A lack of overlapping between the ranges of 95\%CI of any two groups suggests that the domain or the HSTCM can distinguish these groups.

Receiver operating characteristic (ROC) curves [29,30] were plotted for the HSTCM and its three domains. The area under the curve (AUC) was used as an indicator of the ability of the instrument to differentiate participants with or without good self-reported general health status. An AUC of greater than 0.50 indicates a discriminative accuracy to be greater than chance. A perfect discriminative ability would have an AUC of 1.0.

Principal component exploratory factor analysis with Equamax rotation was carried out to assess the underlying structure of the instrument among a set of questionnaire items. Confirmatory factor analysis was further performed to examine whether the data fit the applied model. Goodness of fit of the model was considered to be acceptable if root mean square error of approximation (RMSEA) is less than 0.08. Goodness of fit is good if RMSEA is less than $0.05[31$ ] Comparative fit index (CFI) of greater than 0.95 also indicates a satisfactory goodness of fit [32]. Values are considered statistically significant if $P<0.05$.

\section{Results \\ Range of responses}

From December 2006 to February 2007, 630 participants as a convenience sample were recruited under 11 settings in the Liwan community in Guangzhou, China. Six hundred and twenty-nine participants returned both the HSTCM and WHOQOL-BREF questionnaires, giving an overall response rate of $99.8 \%$. Six of the 629 questionnaires were excluded for not meeting the criteria of logical checking. Among the remaining 623 questionnaires, 611 responded to $80 \%$ or more of the items of both question-

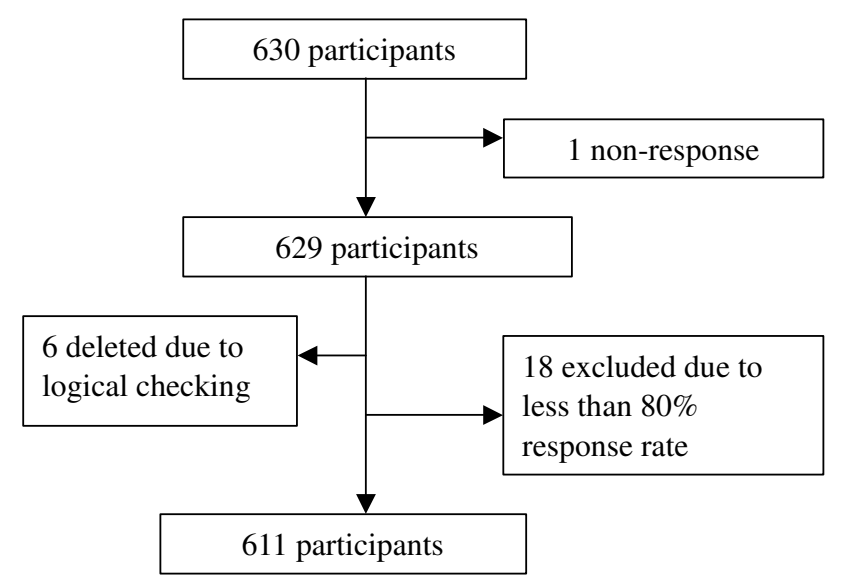

Figure I

Participant selection process. 
naires (Figure 1). Missing values of the items were replaced in accordance with the series mean method.

\section{Demographics}

Among the 611 participants, 58\% were female and the mean age was 49 years. And 35.8\% had completed high school and $15.9 \%$ had completed university or above. All participants were recruited under 11 settings of the Liwan community (Table 1). Among all demographic questionnaires, $66.9 \%$ were self-administered while $8.7 \%$ and $19.6 \%$ were interviewer-assisted and interviewer-administered respectively.

\section{Reliability}

Interviewer reliability

The overall correlation between interviewers in the HSTCM was 0.99 (95\%CI: 0.996-0.999). The correlation coefficient of the PFNE domain was 0.99 (95\%CI: 0.9950.999), the SP domain 0.99 (95\%CI: 0.996-0.999) and the SE domain 0.99 (95\%CI: 0.996-0.999). All the intraclass correlation coefficients (for both the total scale and

Table I: Demographics of the participants

\begin{tabular}{|c|c|c|}
\hline & No & Individual percentage (\%) \\
\hline \multicolumn{3}{|l|}{ Settings of the Liwan community } \\
\hline Dahua & 75 & 12.3 \\
\hline Fulixi & 35 & 5.7 \\
\hline Fulidong & 46 & 7.5 \\
\hline Huicheng & 88 & 14.4 \\
\hline Wenchang flower garden & 46 & 7.5 \\
\hline Fengyuanbei & 50 & 8.2 \\
\hline Community Service centre & 11 & 1.8 \\
\hline Majichong & 100 & 16.4 \\
\hline Huagui & 64 & 10.5 \\
\hline Houfu & 53 & 8.7 \\
\hline Dade & 41 & 6.8 \\
\hline Missing value & 2 & 0.3 \\
\hline \multicolumn{3}{|l|}{ Age } \\
\hline $18-44$ & 245 & 40.1 \\
\hline $45-64$ & 218 & 35.7 \\
\hline 65 and older & 145 & 23.7 \\
\hline Missing value & 3 & 0.5 \\
\hline \multicolumn{3}{|l|}{ Gender } \\
\hline Female & 356 & 58.3 \\
\hline Male & 252 & 41.2 \\
\hline Missing value & 5 & 0.5 \\
\hline \multicolumn{3}{|l|}{ Education } \\
\hline Elementary school & 139 & 22.7 \\
\hline Junior high school & 145 & 23.7 \\
\hline High school & 219 & 35.8 \\
\hline Junior college and above & 97 & 15.9 \\
\hline Missing value & 11 & 1.8 \\
\hline \multicolumn{3}{|l|}{ Interview method } \\
\hline Self-administered & 409 & 66.9 \\
\hline Interviewer-assisted & 53 & 8.7 \\
\hline Interviewer-administered & 120 & 19.6 \\
\hline Missing value & 29 & 4.7 \\
\hline
\end{tabular}

its three domains) were greater than 0.95 (the lower level of $95 \% \mathrm{CI}>0.90$ ), suggesting that the inter-interviewer reliability was satisfactory.

Internal reliability

We calculated the Spearman-Brown split-half reliability coefficient to examine the split-half reliability. The coefficient was 0.81 , indicating a good split-half reliability of the HSTCM.

Internal reliability of the HSTCM and its three domains were estimated with the Cronbach's $\alpha$ coefficient (Table 2).

The Cronbach's $\alpha$ coefficients of the HSTCM domains and the total score of the HSTCM were larger than 0.80. Except the ANC facet, of which the Cronbach's $\alpha$ coefficient was 0.32 , the values of other facets were greater than 0.65 .

\section{Validation}

\section{Convergent validation and discriminative validation}

We carried out convergent validation by correlating the total score of the HSTCM with that of the WHOQOLBREF. The Spearman' rho correlation coefficient (r) was $0.67(P<0.001)$. The three-domain scores showed fair to moderate correlation with the four-domain scores of the WHOQOL-BREF. All the correlations were statistically significant. The physical function domain showed moderate correlation with physical domain $(\mathrm{r}=-0.55, P<0.001)$ and had fair correlation between the psychological domain $(\mathrm{r}=-0.41, P<0.001)$, social domain $(\mathrm{r}=-0.37, P$ $<0.001)$ and environmental domain $(r=-0.31, P<0.001)$ of the WHOQOL-BREF. The spirit domain showed higher correlation with the physical domain $(\mathrm{r}=-0.71, P<$ $0.001)$, psychological domain $(\mathrm{r}=-0.70, P<0.001)$ and social domain $(\mathrm{r}=-0.53, P<0.001)$ of the WHOQOL-

Table 2: Cronbach's $\alpha$ coefficient of the HSTCM domains and facets

\begin{tabular}{lcc}
\hline & Cronbach's $\alpha$ coefficient & No of items \\
\hline HSTCM & 0.93 & 45 \\
I. PFNE & 0.89 & 18 \\
PF & 0.89 & 9 \\
VOC & 0.75 & 2 \\
SU & 0.70 & 2 \\
ANE & 0.75 & 5 \\
2. SP & 0.90 & 14 \\
CC & 0.88 & 6 \\
SC & 0.90 & 2 \\
EG & 0.83 & 4 \\
BAT & 0.68 & 2 \\
3. SE & 0.87 & 13 \\
ACP & 0.76 & 2 \\
ANC & 0.32 & 2 \\
ADBS & 0.89 & 9
\end{tabular}


BREF and fair correlation with the environmental domain ( $\mathrm{r}=-0.47, P<0.001$ ). The social and environmental domain showed only fair correlation with all the four domains with correlation coefficient ranging from -0.32 $(P<0.001)$ in the social and environmental domain to $0.49(P<0.001)$ in the physical domain of the WHOQOL-BREF. The overall HSTCM score displayed significant correlation with all four domains of the WHOQOLBREF. The correlation was moderate with the physical $(\mathrm{r}=$ -0.68, $P<0.001)$ and psychological domain $(\mathrm{r}=-0.62, P$ $<0.001)$ and fair with the social $(\mathrm{r}=-0.47)$ and environmental domain $(\mathrm{r}=-0.43, P<0.001)$ of the WHOQOLBREF (Table 3).

\section{Discriminative validation}

The mean, standard deviation (SD), 95\%CI of each group of the HSTCM and its domains were calculated (Tables 4 and 5). No overlapping of the 95\%CI was found between the participants with good self-reported health status and those with poor self-reported health status in all three domain scores and the overall HSTCM scores. The same results were found between participants with better selfreported health status change and those with worse health status, and between participants with 'not at all/a little degree of medical needs' and those with 'very much/great degree of medical needs'. The overall HSTCM scores and the three domain scores differentiated all three levels of the self-reported health status indicators as well as discriminated the participants with 'not at all/a little degree of medical needs' from those with 'moderate needs'. However, the three domain scores and the overall HSTCM scores did not distinguish the participants with 'moderate medical needs' from those with 'very much/great medical needs'. Moreover, the scores did not distinguish the participants with 'better health statuses' from those with 'no change'.

ROC curves showed the discriminate validation of the instrument (Figure 2). The AUC for the HSTCM and its domains were high and all the lower levels of 95\%CI were greater than 0.5 (Table 6), suggesting that the instrument

Table 3: Correlation between the HSTCM and WHOQOL-BREF domains

\begin{tabular}{lcccc}
\hline HSTCM domains & \multicolumn{4}{c}{ WHOQOL-BREF domains } \\
& Physical & Psychological & Social & Environmental \\
\hline PFNE & -0.55 & -0.41 & -0.37 & -0.31 \\
SP & -0.71 & -0.70 & -0.53 & -0.47 \\
SE & -0.49 & -0.47 & -0.32 & -0.32 \\
Overall HSTCM & -0.68 & -0.62 & -0.47 & -0.43 \\
\hline
\end{tabular}

All correlations are significant at the 0.001 level (2-tailed). In the HSTCM, a higher score means poorer health; in the WHOQOL-BREF, a higher value means better health. discriminated the participants in terms of self-reported health status.

\section{Construct validation}

Exploratory factor analysis

The previous version of the HSTCM [21] did not include appetite and sleep. As appetite and sleep are often used in diagnosis and outcome assessment, the HSTCM focus group decided to include them as additional items of the HSTCM, bringing the total number of items to 47 . However, these two items were not included in the validation analysis. By exploratory factor analysis, 45 items were summed up to nine factors (Table 7).

Result of the Kaiser-Meyer-Olkin (KMO) measure of sampling adequacy test was 0.93, suggesting that the data were suitable for factor analysis [33]. The nine facets explained about $60.8 \%$ of the total variance of the data. The constructs of facet were very similar to those of the previous version. Only SC and CC, belonging to two facets, emerged in the same factor; so did VOC and SU. SC and CC were the facets of the SP domain, while VOC and SU belonged to the PFNE domain. These results showed that the constructs of facets were coherent with structures of the HSTCM domains.

We performed further exploratory factor analysis using scores of the nine facets resulting in three factors, which explains the total variance of $64.1 \%$ (Table 8 ).

\section{Confirmatory factor analysis}

We constructed a model to carry out the confirmatory factor analysis (Figure 3). CFI of the model was above 0.90, while the RMSEA was less than 0.08. The goodness of fit was acceptable.

\section{Discussion}

The properties of the HSTCM were tested in a group of participants in the Liwan community in Guangzhou, China. Measurement properties, internal reliability and inter-interviewer reliability of the HSTCM and its domains were satisfactory. The HSTCM had mild convergence with the WHOQOL-BREF (with a moderate correlation). The overall HSTCM scores and most of the domain scores discriminated groups of participants with known differences in health status. Confirmatory factor analysis showed a good structure fitness of the domains and overall structure.

In the reliability test, Cronbach's $\alpha$ was low in subscale ANC (0.32). As the items in the ANC facet met the selection criteria and Cronbach's $\alpha$ was considered to be acceptable on the whole scale and three domains' level; we may need further evidence before removing ANC from the scale. 
Table 4: Discriminative ability of the HSTCM in terms of levels of health status

\begin{tabular}{|c|c|c|c|c|}
\hline & \multirow[b]{2}{*}{ No. } & \multicolumn{3}{|c|}{ Scores of the HSTCM } \\
\hline & & Mean & SD & $95 \% \mathrm{Cl}$ \\
\hline \multicolumn{5}{|c|}{ I. Self-reported general health status } \\
\hline Good/very good & 268 & 90.18 & 18.56 & $87.86-92.69$ \\
\hline Neither poor nor good & 263 & 114.46 & 19.16 & $112.46-117.40$ \\
\hline Poor/very poor & 78 & 132.92 & 21.50 & $128.03-137.80$ \\
\hline Missing value & 2 & - & - & - \\
\hline \multicolumn{5}{|c|}{ 2. Self-reported health status change } \\
\hline Better & 102 & 93.92 & 24.21 & $88.92-99.82$ \\
\hline No change & 283 & 102.17 & 22.72 & $99.73-105.44$ \\
\hline Worse & 226 & 116.25 & 22.50 & $113.54-119.76$ \\
\hline Missing value & 0 & - & - & - \\
\hline \multicolumn{5}{|l|}{ 3. Degree of medical needs } \\
\hline Not at all/a little & 331 & 97.56 & 21.33 & $94.47-99.42$ \\
\hline A moderate amount & 189 & 115.97 & 22.17 & $113.36-119.86$ \\
\hline A great amount & 88 & 117.20 & 26.98 & $113.44-125.45$ \\
\hline Missing value & 3 & - & - & - \\
\hline
\end{tabular}

Self-reported general health status is item 21 of the HSTCM; self-reported health status change is item 22 of the HSTCM; degree of medical needs is item 4 of the WHOQOL-BREF.

Table 5: Discriminate ability of the domains in terms of levels of health status

\begin{tabular}{|c|c|c|c|c|c|c|c|c|c|c|}
\hline & \multirow[t]{2}{*}{ No } & \multicolumn{3}{|c|}{ Scores of PFNE } & \multicolumn{3}{|c|}{ Scores of SP } & \multicolumn{3}{|c|}{ Scores of SE } \\
\hline & & Mean & SD & $95 \% \mathrm{Cl}$ & Mean & SD & $95 \% \mathrm{Cl}$ & Mean & SD & $95 \% \mathrm{Cl}$ \\
\hline \multicolumn{11}{|c|}{ I. Self-reported general health status } \\
\hline Good/very good & 268 & 34.8 & 8.80 & $33.5-35.8$ & 27.9 & 6.85 & $27.3-29.0$ & 27.5 & 7.59 & $26.5-28.5$ \\
\hline Neither poor nor good & 263 & 45.3 & 9.82 & $44.4-46.9$ & 36.6 & 6.60 & $35.9-37.6$ & 32.6 & 7.68 & $31.5-33.5$ \\
\hline Poor/very poor & 78 & 51.2 & 11.77 & $49.1-54.6$ & 44.4 & 6.78 & $42.9-45.9$ & 36.5 & 8.09 & $34.8-38.6$ \\
\hline Missing value & 2 & - & - & - & - & - & - & - & - & - \\
\hline \multicolumn{11}{|c|}{ 2. Self-reported health status change } \\
\hline Better & 102 & 38.0 & 11.15 & $35.4-40.3$ & 27.0 & 8.46 & $25.6-29.4$ & 28.9 & 8.35 & $27.2-30.9$ \\
\hline No change & 283 & 39.4 & 11.07 & $38.3-41.1$ & 32.9 & 7.87 & $32.1-34.0$ & 29.8 & 8.03 & $28.8-30.8$ \\
\hline Worse & 226 & 45.5 & 10.90 & $44.2-47.3$ & 37.8 & 7.79 & $36.8-39.0$ & 33.0 & 8.26 & $31.8-34.1$ \\
\hline Missing value & 0 & - & - & - & - & - & - & - & - & - \\
\hline \multicolumn{11}{|c|}{ 3. Degree of medical needs } \\
\hline Not at all/a little & 331 & 37.8 & 9.61 & $36.3-38.6$ & 30.8 & 8.04 & $30.0-31.7$ & 29.0 & 7.87 & $27.8-29.6$ \\
\hline A moderate amount & 189 & 46.0 & 11.25 & $44.8-48.0$ & 37.2 & 7.60 & $36.3-38.6$ & 32.7 & 7.94 & $31.6-33.9$ \\
\hline A great amount & 88 & 45.7 & 13.30 & $43.6-49.6$ & 37.4 & 9.56 & $36.1-40.3$ & 34.1 & 8.95 & $32.6-36.6$ \\
\hline Missing value & 3 & - & - & - & - & - & - & - & - & - \\
\hline
\end{tabular}

Self-reported general health status is item 21 of the HSTCM; self-reported health status change is item 22 of the HSTCM; degree of medical needs is item 4 of the WHOQOL-BREF.

PFNE: physical function under natural environment domain

SP: spirit domain

SE: social and environment domain 
Table 6: Areas under the ROC curves for the HSTCM and its domains in discriminate performance between participants with and without good self-reported general health status

\begin{tabular}{|c|c|c|c|c|c|}
\hline \multirow[t]{2}{*}{ Variable } & \multirow[t]{2}{*}{ Area under ROC curve } & \multirow[t]{2}{*}{ SE } & \multirow[t]{2}{*}{ Significant level } & \multicolumn{2}{|c|}{$95 \% \mathrm{Cl}$} \\
\hline & & & & Lower & Upper \\
\hline PFNE & 0.81 & 0.02 & $<0.01$ & 0.78 & 0.85 \\
\hline SP & 0.85 & 0.02 & $<0.01$ & 0.82 & 0.88 \\
\hline SE & 0.71 & 0.02 & $<0.01$ & 0.67 & 0.76 \\
\hline HSTCM & 0.85 & 0.02 & $<0.01$ & 0.82 & 0.88 \\
\hline
\end{tabular}

Null hypothesis: true area $=0.5$ (Smaller test result indicates more positive test.)

Nonparametric distribution $(95 \% \mathrm{Cl})$

\section{ROC curve}

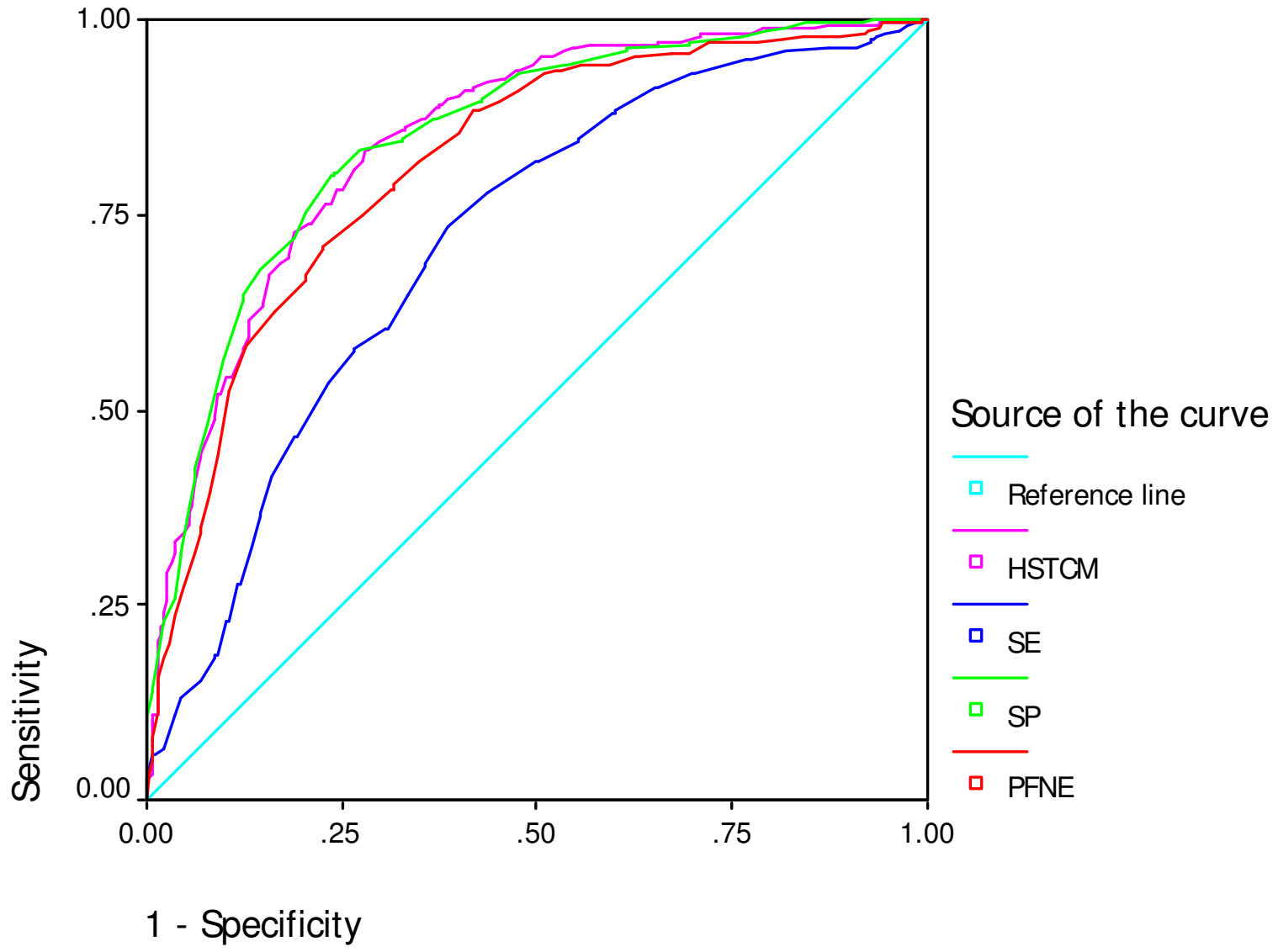

Figure 2

ROC curves for the HSTCM and its domains in discriminating performance between participants with good self-reported general health status and those without. HSTCM: Health Scale of Traditional Chinese Medicine; SE: social and environment domain; SP: spirit domain; PFNE: physical function under natural environment domain. 
Table 7: Exploratory factor analysis of the nine facets of the HSTCM

\begin{tabular}{|c|c|c|c|c|c|c|c|c|c|}
\hline & 1 & 2 & 3 & 4 & 5 & 6 & 7 & 8 & 9 \\
\hline \multicolumn{10}{|l|}{ I. PF } \\
\hline Palpitation (TI4) & 0.753 & & & & & & & & \\
\hline Chest distress (TI5) & 0.752 & & & & & & & & \\
\hline Disorder of the taste (TI8) & 0.709 & & & & & & & & \\
\hline Tinnitus (T20) & 0.677 & & & & & & & & \\
\hline Thirst (TI7) & 0.666 & & & & & & & & \\
\hline Dizziness $\left(T_{-} \mid 3\right)$ & 0.652 & & & & & & & & \\
\hline Pain $\left(T \_16\right)$ & 0.652 & & & & & & & & \\
\hline Disorder of perspiration (TI2) & 0.638 & & & & & & & & \\
\hline Gastrointestinal disorder (TI9) & 0.618 & & & & & & & & \\
\hline \multicolumn{10}{|l|}{ 2. SDSC, CC } \\
\hline Satisfaction of appearance (T3I) & & 0.781 & & & & & & & \\
\hline Satisfaction of body figure (T30) & & 0.774 & & & & & & & \\
\hline Concerning the future (T29) & & 0.749 & & & & & & & \\
\hline Meaning of life (T32) & & 0.736 & & & & & & & \\
\hline Contented sensation of work (T28) & & 0.703 & & & & & & & \\
\hline Vivid (T26) & & 0.689 & & & & & & & \\
\hline Joy (T25) & & 0.678 & & & & & & & \\
\hline Confidence (T27) & & 0.674 & & & & & & & \\
\hline \multicolumn{10}{|l|}{ 3. ADBS } \\
\hline Great concern (T39) & & & 0.732 & & & & & & \\
\hline Upset (T4I) & & & 0.721 & & & & & & \\
\hline Afraid (T38) & & & 0.696 & & & & & & \\
\hline Tension and tired (T42) & & & 0.683 & & & & & & \\
\hline Scare $(\mathrm{T} 40)$ & & & 0.669 & & & & & & \\
\hline Worry (T36) & & & 0.599 & & & & & & \\
\hline Hesitate (T43) & & & 0.595 & & & & & & \\
\hline Insomnia (T37) & & & 0.579 & & & & & & \\
\hline Annoyance (T35) & & & 0.531 & & & & & & \\
\hline \multicolumn{10}{|l|}{ 4. EG } \\
\hline Self-reported health change (T22) & & & & 0.749 & & & & & \\
\hline Energy (T23) & & & & 0.748 & & & & & \\
\hline Self-reported general health(T2I) & & & & 0.680 & & & & & \\
\hline Physical strength (T24) & & & & 0.675 & & & & & \\
\hline \multicolumn{10}{|l|}{ 5. ANE } \\
\hline Cold weather (T2) & & & & & 0.697 & & & & \\
\hline Weather change ( $\mathrm{TI})$ & & & & & 0.639 & & & & \\
\hline Hot weather (T3) & & & & & 0.615 & & & & \\
\hline Season change (T4) & & & & & 0.612 & & & & \\
\hline Circumstance of temperature difference (T5) & & & & & 0.586 & & & & \\
\hline \multicolumn{10}{|l|}{ 6. VOC, SU } \\
\hline Urine $(T I 0)$ & & & & & & 0.677 & & & \\
\hline Stool (TII) & & & & & & 0.596 & & & \\
\hline Voice (T7) & & & & & & 0.630 & & & \\
\hline Voice change (T6) & & & & & & 0.452 & & & \\
\hline \multicolumn{10}{|l|}{ 7. ACP } \\
\hline Nervous (T44) & & & & & & & 0.773 & & \\
\hline Adjustment disorders (T45) & & & & & & & 0.753 & & \\
\hline \multicolumn{10}{|l|}{ 8. BAT } \\
\hline Activities of daily life (T33) & & & & & & & & 0.686 & \\
\hline Focus attentions (T34) & & & & & & & & 0.562 & \\
\hline \multicolumn{10}{|l|}{ 9. ANC } \\
\hline Anti-disturbance capability (T46) & & & & & & & & & 0.726 \\
\hline Noisy environment (T47) & & & & & & & & & 0.466 \\
\hline
\end{tabular}

Extraction method: principal component analysis. Equamax rotation with Kaiser Normalization, sorted by size, factor loading $<0.4$ suppressed 
Table 8: Exploratory factor analysis of the three domains of the HSTCM

\begin{tabular}{lccc}
\hline & 1 & 2 & 3 \\
\hline PF & 0.764 & & \\
ANE & 0.776 & & \\
VOC, SU & 0.632 & & \\
SC, CC & & 0.814 & \\
EG & & 0.618 & \\
BAT & & 0.771 & 0.771 \\
ACP & & & 0.755 \\
ANC & & 0.518 \\
ADBS & & & \\
\hline
\end{tabular}

Extraction method: principal component analysis Equamax rotation with Kaiser Normalization, sorted by size, factor loading $<0.4$ suppressed

In this study, we used the ROC analysis to evaluate the discriminate ability of the HSTCM. The AUC indicates that the HSTCM discriminate better than chance between groups with and without good self-reported health status. Therefore, the results of ROC analysis support the clinical validity of the HSTCM. However, this discriminate ability should not be confused with that of diagnostic instruments. Health status measures are not intended to be used at an individual patient level [34].

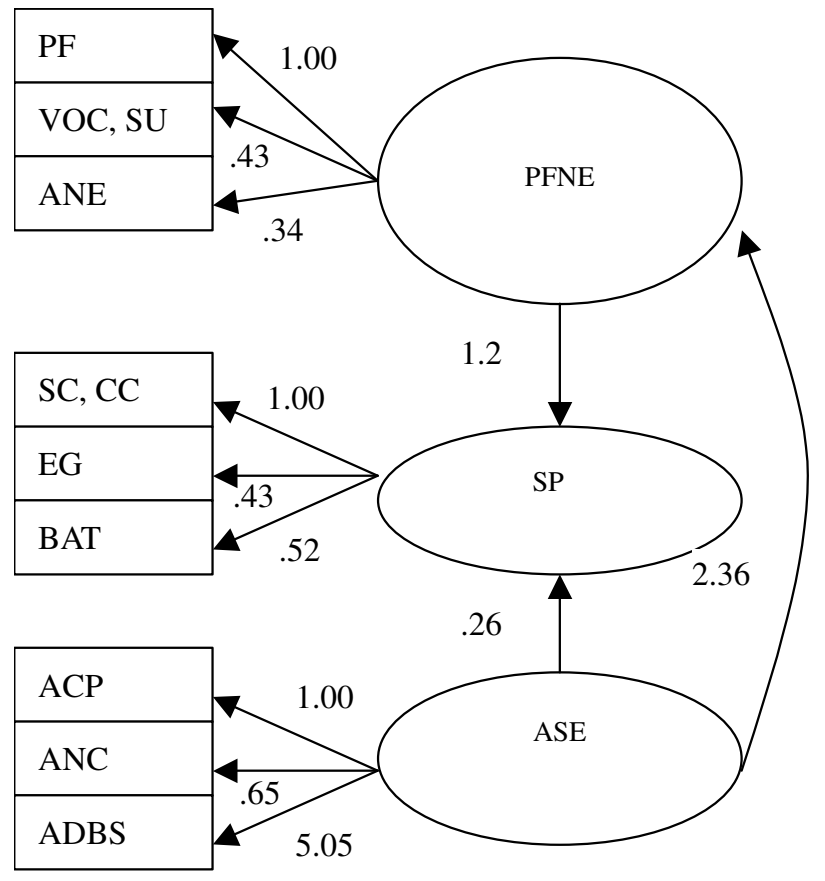

Chi-square $=337.78, \mathrm{df}=35, \mathrm{p}=.00$

$\mathrm{CFI}=0.954, \mathrm{RMSEA}=0.067$

Figure 3

Model of the confirmatory factor analysis between the HSTCM domains and facets.
Construct validation is an ongoing process. The more frequently an instrument is used, the greater our confidence is in its validation [35]. Comparing the previous study [21] with the present one, we found that the construct validities of two independent samples were similar. Similar constructs in two independent studies strengthen the construct validation for the HSTCM. We may find some similar constructs in other health related QOL instruments based on Chinese medicine theory [16].

Items from SC and CC had similar meanings in terms of the HSTCM developmental theory, as did VOC and SU, which may be explained by the exterior-interior relations [36] between the large intestine meridian and lung meridian. The exterior-interior relations of the two meridians not only strengthen the connection between this specific pair of meridians, but also promote the large intestine/ lung pair to coordinate with each other physiologically and influence each other pathologically. Items of the VOC facet are key indicators of the status of lung, while the SU facet contains an important predictor of the large intestine.

No test-retest reliability was conducted in the present study; however, results from the previous study suggest good test-retest reliability [22].

The attribute of 'responsiveness' is also considered as a component of a scale validation [37]. Based on the discriminative validation and measures of ROC, we think that the responsiveness of the scale is acceptable [38]. However, we did not estimate the parameter to compare the before-after changes caused by a given intervention, which means the inference may be limited.

In this study, participants were selected from a community by convenience sampling which is widely used in psychometric property testing, especially those of health scales [39-43]. However, a convenience sample is less representative than a random sample and may limit the generalizability of this study.

We did not use item response theory (IRT) in developing and evaluating the HSTCM because the advantage of the IRT methods over traditional methods was not clear to us [44]. However, we think that IRT methods can be used to refine the scale. Generalizability theory (GT) is another powerful tool in analyzing scale reliability with complicated sources of measurement biases. Further studies with IRT to analyze item characteristic of the instrument and with GT to evaluate the validation of the HSTCM are warranted. 


\section{Conclusion}

The HSTCM meets the basic requirements for a generic health scale and complements the existing health measurement scales for Chinese medicine health care.

\section{Abbreviations}

HSTCM: Health Scale of Traditional Chinese Medicine; WHOQOL-BREF: World Health Organization Quality of Life Measure-Abbreviated Version; SF-36: MOS 36-Item Short Form; PRO: patient reported outcomes; SOP: standard operating procedure; iHSTCM: initial Health Scale of Traditional Chinese Medicine; ICC: intraclass correlation coefficient; PFNE: physical function under natural environment domain; SP: spirit domain; SE: social and environment domain; PF: physical functioning facet; VOC: voice facet; SU: stool and urine facet; ANE: adaptability of natural environment facet; $\mathrm{CC}$ : confidence and content facet; SC: self-confidence facet; EG: energy facet; BAT: basic ability of thinking facet; ACP: ability of communicating with people facet; ANC: adaptability of noisy condition facet; ADBS: ability of dealing with bad stimulations facet; ROC: receiver operating characteristic; AUC: area under curve; CFI: comparative fit index; RMSEA: root mean square error of approximation; IRT: item response theory; GT: generalizability theory.

\section{Competing interests}

The authors declare that they have no competing interests.

\section{Authors' contributions}

SLL and DRW conceived the study design, drafted the protocol and manuscript. DRW and LJZ arranged and conducted the training and investigation. DRW did data management and data analysis. XFG, ZHW, WXL and AHO were members of the HSTCM focus group; together with KJC they provided methodological insights. GQZ was in charge of the recruitment of the interviewers. All authors read and approved the final version of the manuscript.

\section{Additional material}

\section{Additional file 1}

The items of the HSTCM in their original Chinese. The HSTCM consists of three domains, namely physical function under natural environment (PFNE), spirit (SP) and social environment (SE), and 2 additional items.

Click here for file

[http://www.biomedcentral.com/content/supplementary/17498546-4-8-S1.doc]

\section{Acknowledgements}

This work was supported by the State Administration of Traditional Chinese Medicine of the People's Republic of China (No.04-05JP50), the
Finance Department of Guangdong Province (No. 2 [2006] 143) and the Guangzhou University of Chinese Medicine (No. 84). We are grateful to Drs Zhigang Zhong, Nuo Su and others from the Health Service Centre of Fengyuan Road, Liwan community, Guangzhou, China for their kind assistance in the investigation. We also thank all the interviewers and participants who took part in this study.

\section{References}

I. Greenfield S, Nelson EC: Recent developments and future issues in the use of health status assessment measures in clinical settings. Med Care 1992, 30(5 Suppl):MS23-MS4I.

2. Guyatt G, Veldhuyzen V, Sander J, Feeny D, Patrick D: Measuring quality of life in clinical trials: a taxonomy and review. CMA] 1989, 140:|44|-|448.

3. Guyatt G, Kirshner B, Jaeschke R: Measuring health status: what are the necessary measurement properties. J Clin Epidemiol 1992, 45: I34I-I345.

4. Stewart AL, Greenfield S, Hays RD: Functional status and wellbeing of patients with chronic conditions: results from the Medical Outcomes Study. JAMA 1989, 262:907-913.

5. Stewart AL, Hays RD, Ware JE: The MOS Short-form General Health Survey. Reliability and validity in a patient population. Med Care 1988, 26:724-35.

6. Ware JE, Shebourne CD: The MOS 36-item short form health survey(SF-36): I. Conceptual framework and item selection. Med Care 1992, 30(6):473-483.

7. The WHOQOL Group Development of the WHOQOL: Rationale and current status. Int J Ment Health 1994, 23(3):24-56.

8. Wilke RJ, Burke LB, Erickson P: Measuring treatment impact: a review of patient-reported outcomes and other efficacy endpoints in approved product labels. Control Clin Trials 2004, 25:535-552.

9. World Health Organization: WHO Traditional Medicine Strategy 20022005 (document reference WHO/EDM/TRM/2002.I) World Health Organization; Geneva; 2002: I-2.

10. Eisenberg DM, Davis RB, Ettner SL, Appel S, Wilkey S, Van Rompay $M$, Kessler RC: Trends in alternative medicine use in the United States, 1990-1997: results of a follow-up national survey. JAMA 1998, 280:I569-I575.

II. MacLennan AH, Wilson DH, Taylor AW: Prevalence and cost of alternative medicine in Australia. Lancet 1996, 347:569-573.

12. Fisher $P$, Ward A: Medicine in Europe: complementary medicine in Europe. BM/ 1994, 309:107-III.

13. Wu DR, Guo XF, Lai SL: Assessment of quality of life and its application in evaluating therapeutic effect of traditional Chinese medicine. Guangzhou Zhongyiyao Daxue Xuebao 2002, I9(4):256-260.

14. Zhao L, Chen JQ, Liang GH, Liu FB: Quality of life and Chinese medicine: the development of health status measures for Chinese medicine. Zhongguo Zhong Xi Yi Jie He Za Zhi. 2003, 9(2): $136-138$.

15. Editorial Board of Dictionary of Chinese Medicine: Brief Dictionary of Chinese Medicine (Revised version) Beijing: Peoples' Medical Publishing House; 1979:384.

16. Leung KF, Liu FB, Zhao L, Fang JQ, Chan K, Lin LZ: Development and validation of the Chinese Quality of Life Instrument. Health Qual Life Outcomes 2005, 3:26.

17. Bell IR, Cunningham V, Caspi O, Meek P, Ferro L: Development and validation of a new global well-being outcomes rating scale for integrative medicine research. BMC Complement Altern Med 2004, 4: I.

18. Scientific Advisory Committee of the Medical Outcome Trust: Assessing health status and quality-of-life instruments: Attributes and review criteria. Qual Life Res 2002, I I (3): 193-205.

19. Earl Babbie: The practice of social research. 10th Chinese language edition Translated by Zeqi Qiu. Beijing: Huaxia Publishing House; 2005:I29-|45.

20. Wu DR, Lai SL: Exploration on Health Concept of TCM and the Operationalization of Its Measurement. Zhongguo Zhongxiyi Jiehe Zazhi 2007, 27(2): I74-I77.

21. Wu DR, Lai SL, Guo XF, Wen ZH, Liang WX, Yang XB, Wang XY, Lao YR, Ou AH, Zhang GQ: Establishment and initial evaluation 
of health scale of traditional Chinese medicine. Zhongguo Zhongxiyi Jiehe Zazhi 2007, 27(9):847-850.

22. Wu DR, Lai SL, Guo XF, Wen ZH, Liang WX: Reliability and validity of the Health Scale of Traditional Chinese Medicine. Zhongxiyi Jiehe Xuebao 2008, 6(7):682-689.

23. Streiner DL, Norman GR: Health measurement scales: a practical guide to their development and use 2nd edition. New York: Oxford medical publications; 1995. 152, 8

24. McHorney CA: Measuring and monitoring general health status in elderly persons: practical and methodological issues in using the SF-36 Health Survey. Gerontologist 1996, 36:57I-583.

25. The WHOOOL Group: Development of the World Health Organization WHOQOL-BREF quality of life assessment. Psychol Med 1998, 28(3):55I-558.

26. Ministry of Health of the People's Republic of China: Quality of life questionnaire: standard criterion of the health trade of the People's Republic of China (WS/TI I9). Beijing 1999: I-19.

27. Wang JL: Clinical Epidemiology-Design, Measurement and Evaluation of Clinical Research 2nd edition. Shanghai: Shanghai Scientific and Technical Publishers; 200I:363-367.

28. Carmines EG, Zeller RA: Reliability and validity assessment Beverly Hills: Sage; 1979:9-51.

29. Hanley JA, McNeil BL: The meaning and use of the area under a receiver operating characteristic curve. Radiology 1982, I 43(I):29-36.

30. Centor RM: Signal detectability: The use of ROC curves and their analyses. Med Decis Making I99I, I I(2): 102-106.

3I. Browne MW, Cudeck R: Alternative ways of assessing model fit. In Testing structural equation models Edited by: Bollen KA, Long JS Newbury Park: Sage Publications; 1993:136-162.

32. Hu LT, Bentler PM: Fit indices in covariance structure modeling: Sensitivity to underparameterized model misspecification. Psychol Med 1998, 3:424-453.

33. Zhang WT: Advanced SPSSII tutorial of Statistic Analysis Bejing: Beijing Hope Electronic Press; 2002: 198.

34. McHorney CA, Tarlov AR: Individual-patient monitoring in clinical practice: Are available health status surveys adequate? Qual Life Res 1995, 4(4):293-307.

35. Guyatt GH, Feeny DH, Patrick DL: Measuring Health-related quality of life. Ann Int Med 1993, I I 8(8):622-629.

36. Zhu WF: Diagnosis Methods of Traditional Chinese Medicine Beijing: China Press of Traditional Chinese Medicine; 2002:144-I46.

37. Fitzpatrick R, Davey C, Buxton MJ, Jones DR: Evaluating patientbased outcome measures for use in clinical trials. Health Technol Assess 1998, 2(14):i-iv.

38. Deyo RA, Centor RM: Assessing the responsiveness of functional scales to clinical change: an analogy to diagnostic test performance. J Chronic Dis 1986, 39:897-906.

39. Molzahn AE, Page G: Field testing the WHOQOL-100 in Canada. Can J Nurs Res 2006, 38(3): I06-123.

40. Davis AH, Figueredo AJ, Fahy BF, Rawiworrakul T: Reliability and validity of the exercise self-regulatory efficacy scale for individuals with chronic obstructive pulmonary disease. Heart Lung 2007, 36(3):205-216.

41. Shuldham C, Theaker C, Jaarsma T, Cowie MR: Evaluation of the European Heart Failure Self-care Behaviour Scale in a United Kingdom population. J Adv Nurs 2007, 60(I):87-95.

42. Kartala A, Ozsoy SA: Validity and reliability study of the Turkish version of Health Belief Model Scale in diabetic patients. Int J Nurs Stud 2007, 44(8): I 447-I458.

43. Varni JW, Limbers CA: The PedsQL ${ }^{\mathrm{TM}}$ Multidimensional Fatigue Scale in young adults: feasibility, reliability and validity in a University student population. Qual Life Res 2008 17:105-114.

44. Fayers PM: Applying item response theory and computer adaptive testing: the challenges for health outcomes assessment. Qual Life Res 2007, I6:187-194.
Publish with Bio Med Central and every scientist can read your work free of charge

"BioMed Central will be the most significant development for disseminating the results of biomedical research in our lifetime. "

Sir Paul Nurse, Cancer Research UK

Your research papers will be:

- available free of charge to the entire biomedical community

- peer reviewed and published immediately upon acceptance

- cited in PubMed and archived on PubMed Central

- yours - you keep the copyright

Submit your manuscript here:

http://www.biomedcentral.com/info/publishing_adv.asp
BioMedcentral 